\title{
Efficient Immobilization of a Cadmium Chemosensor in a Thin Film: Generation of a Cadmium Sensor Prototype
}

\author{
R. Todd Bronson, ${ }^{*, \dagger}$ David J. Michaelis, Randy D. Lamb, Ghaleb A. \\ Husseini, \\ Paul B. Farnsworth, Matthew R. Linford, Reed M. Izatt, Jerald S. \\ Bradshaw, and Paul B. Savage
}

Physical Science Department, College of Southern Idaho, Twin Falls, Idaho 83301, and Department of Chemistry and Biochemistry, Brigham Young UniVersity, ProVo, Utah84602tbronson@csi.edu
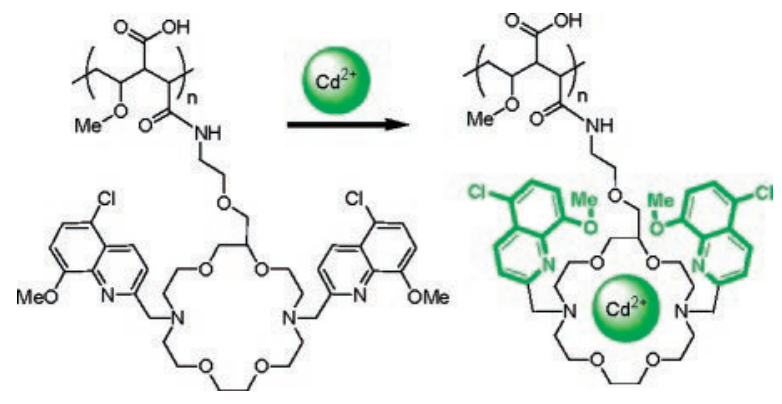

The development of an ion-selective chemosensor for $\mathrm{Cd}^{2+}$ allows generation of a "real-time" sensor. Immobilization of the chemosensor on quartz was achieved in a simple monolayer and in a thin film using a polymer intermediary. As intended, the thin film contains much more chemosensor than the monolayer and provides measurable responses to aqueous $\mathrm{Cd}^{2+}$ concentrations below $1 \mu \mathrm{M}$. Alkali and alkaline earth ions do not interfere with $\mathrm{Cd}^{2+}$ sensing; $\mathrm{Zn}^{2+}$ and $\mathrm{Cu}^{2+}$ are potential interferents.

The detrimental effects of cadmium on human health are increasingly being recognized; chronic cadmium exposure can cause renal dysfunction, calcium metabolism disorders, and an increased incidence of certain forms of cancer, ${ }^{1}$ possibly due to direct inhibition of DNA mismatch repair by cadmium. ${ }^{2}$ Anthropogenic sources of cadmium in the environment include mining and smelting metal ores, fossil fuel combustion, and metal industries. ${ }^{3}$ In addition, cadmium is often found in high concentrations in phosphate mined for use as fertilizer ${ }^{4}$ and can be concentrated in sewage sludge. ${ }^{3}$ Identification of cadmiumcontaminated sewage and fertilizer would prove to be very useful in limiting human exposure, as would identification of other environmental sources of cadmium. Most current methods of quantifying cadmium are labor intensive and expensive, ${ }^{2,5}$ and an attractive means of improving monitoring of metal ion concentrations would be the use of simple, inexpensive, and portable sensors. This need has been recognized, and a number of potential means of measuring specific metal ion concentrations using onsite, inexpensive facilities have been investigated.6 These methods have employed ion-selective electrodes or colorimetric measurements; however, they suffer from high detection limits or the need for preconcentration procedures. Extensive efforts have been made to prepare and characterize chemosensors for specific metal ions with the intent of incorporating these molecules in sensors. 7 For example, He et al.,8 recently reported the use of a fluorescent, ionselective chemosensor in a sensor capable of measuring potassium concentrations in the millimolar range in whole blood. Reinhoudt and co-workers9 immobilized a sodium selective chemosensor in a monolayer on quartz and observed small changes in fluorescence in the presence of sodium acetate. 

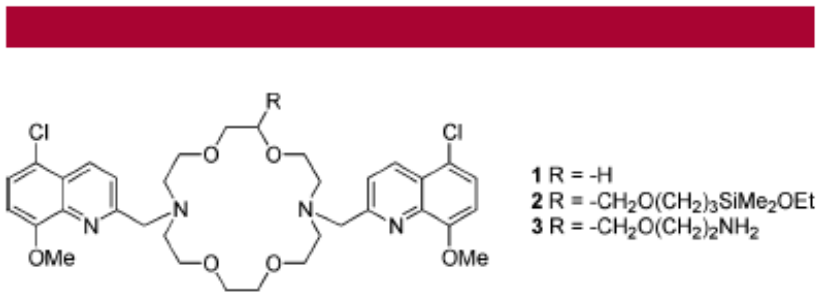

Figure 1. Structure of chemosensor $\mathbf{1}$ and appended forms $\mathbf{2}$ and

We recently reported the synthesis and characterization of 1 (Figure 1) as a selective chemosensor for cadmium. ${ }^{10}$ This compound selectively binds and responds to $\mathrm{Cd}^{2+}$ via a large change in fluorescence emission $\left.\left.\left(\log K_{\mathrm{a}}\right) 6.1, \Phi\right) 0.66\right)$. The observed fluorescence enhancement upon complexation is believed to result from an efficient interruption of photoinduced electron transfer (PET) between the amino groups and the chromophore ring systems by $\mathrm{Cd}^{2+}$. We now report immobilization of this chemosensor on quartz in a monolayer and in a thin film, as well as characterization of the resulting materials for use in a cadmium sensor.

For preparation of a monolayer of $\mathbf{1}$, we appended ethoxydimethylsilane onto the chemosensor, starting with known $4^{11}$ to give $\mathbf{2}$ (Scheme 1). This allowed monolayer tion. ${ }^{12}$ To increase the number of reactive groups on the surface, we also immobilized the chemosensor through an intermediary polymer using amine-appended chemosensor 3. Treatment of quartz slides with 3aminopropyltriethoxysilane (neat) at elevated temperature provided an aminefunctionalized surface, which was in turn reacted with poly(methylvinyl ether-alt-maleic anhydride) (average MW ) ca. 1250 000) in an aggregated form in THF and $\mathrm{CH}_{2} \mathrm{Cl}_{2}$. The intent was to leave anhydride groups in the polymer free for later reaction with 3 .

Characteristic UV absorptions of $\mathbf{2}$ and $\mathbf{3}$ were used to gauge the amount of chemosensor immobilized in the monolayer and thin film. Slides derived from $\mathbf{2}$ and $\mathbf{3}$ gave absorbances of approximately 0.01 and $0.16 \mathrm{AU}$ at $250 \mathrm{~nm}$, respectively, indicating that the intermediary polymer markedly increased the number of reactive sites available for immobilization. Repeated experiments and UV characterization demonstrated that the immobilization procedures were reproducible. X-ray photoelectron spectroscopy confirmed the presence of nitrogen and chlorine in the thin film, and the N/Si ratio provided an estimate of film thickness of $100 \AA$.

The following were key issues in studying the behaviors of the monolayer and thin film: increases in fluorescence concomitant with exposure to $\mathrm{Cd}^{2+}$, apparent kinetics of complex formation and dissolution, and effects of potential interferents. To study these issues, we used a flow-through cell through which we could pass solutions while observing fluorescence at the characteristic emission wavelength of the 1- $\mathrm{Cd}^{2+}$ complex. In the cell, slides were held at $40^{\circ}$ withrespect to the excitation source, and flow rates were 3
$\mathrm{mL} / \mathrm{min}$ with a cell volume of approximately $1.6 \mathrm{~mL}$. To ensure that $\mathrm{pH}$ changes did not interfere with measurements, solutions were buffered with sodium acetate $(10 \mathrm{mM}, \mathrm{pH}$ 5.1).

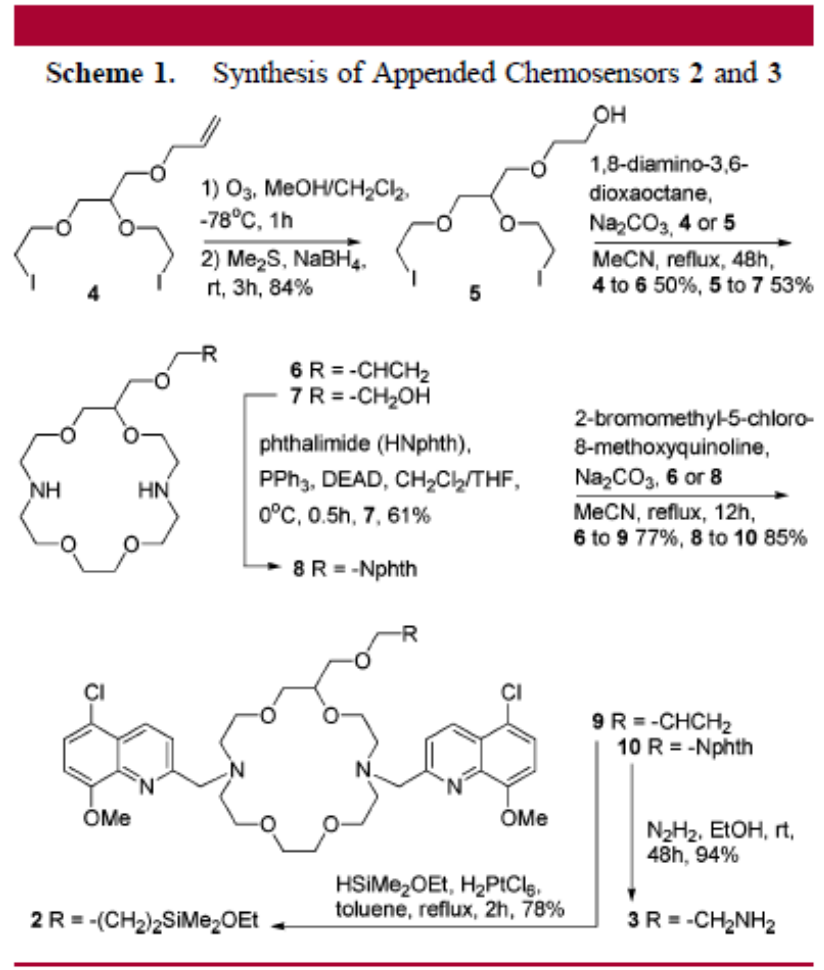

When subjected to solutions of $\mathrm{Cd}^{2+}$, the monolayer containing 2 yielded only modest increases in intensity over background fluorescence $(<400$ CPS change in the presence

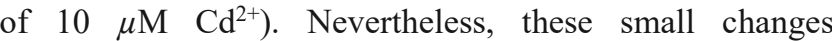
correlated roughly with $\mathrm{Cd}^{2+}$ concentration, and responses were relatively rapid. However, the small increase in fluorescence intensity suggested that greater quantities of immobilized chemosensor might be better suited for use in a sensor.

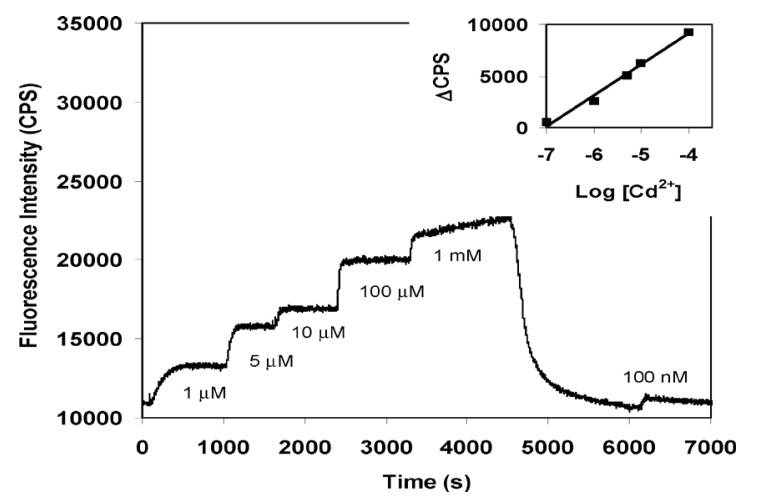

Figure 2. Response of thin film containing 3 to $\mathrm{Cd}^{2+}$ in aqueous sodium acetate buffer (10 mM, pH 5.1). $\left.\left.\lambda_{\mathrm{ex}}\right) 335 \mathrm{~nm} ; \lambda_{\mathrm{em}}\right) 450 \mathrm{~nm}$; slit widths (ex and em) ) $2 \mathrm{~nm}$. 
The thin film containing $\mathbf{3}$ gave a large fluorescence increase in the presence of $\mathrm{Cd}^{2+}$ (Figure 2). Response times to the presence of $\mathrm{Cd}^{2+}$ were about $1 \mathrm{~min}$, while approximately $5 \mathrm{~min}$ was required for the fluorescence to return to baseline (these response times include time required to equilibrate the solution in the cell). The thickness of the monolayer and the dissociation rate of $\mathrm{Cd}^{2+}$ likely contribute to the rate of response. With the thin film, it was possible to detect readily the presence of $\mathrm{Cd}^{2+}$ at $1 \mu \mathrm{M}$, and a small response was observed at $100 \mathrm{nM} \mathrm{Cd}^{2+}$. At the highest concentration $(1 \mathrm{mM})$, a slow increase in fluorescence intensity was observed. This increase may be caused by formation of a higher-order complex with greater quantum yield. A plot of fluorescence response vs $\left[\mathrm{Cd}^{2+}\right]$ indicated that this relationship is logarithmic in nature (inset, Figure 2) over the concentration range studied $\left(100 \mathrm{nM}\right.$ to $\left.1 \mathrm{mM} \mathrm{Cd}^{2+}\right)$, which may be due to energy transfer among fluorophores leading to nonradiative decay and loss of affinity of the thin film for the target cation as the ionic nature of the thin film increases.

To observe reversibility of binding and dissociation, the thin film was alternatively exposed to a solution of $\mathrm{Cd}^{2+}$

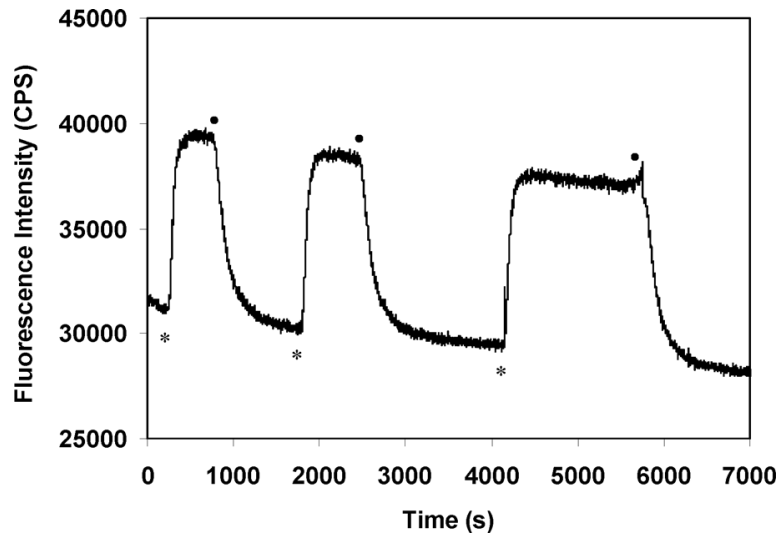

Figure 3. Fluorescent response of thin film containing 3 to $\mathrm{Cd}^{2+}(10$ $\mu \mathrm{M})$ in aqueous sodium acetate buffer $\left.(10 \mathrm{mM}, \mathrm{pH} 5.1) . \lambda_{\mathrm{ex}}\right) 335$ $\left.\mathrm{nm} ; \lambda_{\mathrm{em}}\right) 450 \mathrm{~nm}$; slit widths (ex and em) ) $2 \mathrm{~nm}$. (*) Flow of $\mathrm{Cd}^{2+}$ solution initiated. $(\bullet)$ Flow of $\mathrm{Cd}^{2+}$-free buffer initiated.

and sodium acetate buffer (Figure 3). In these experiments, we observed a gradual loss of fluorescence intensity at both the baseline and with the thin film exposed to $\mathrm{Cd}^{2+}$. This loss of fluorescence proved to be due to photobleaching of the fluorophore, which remained constant with loss of approximately $0.27 \%$ of the fluorescent signal per minute of exposure to the excitation radiation. It is anticipated that it would be possible to compensate for this loss in signal in a functional sensor.

Studies then focused on correlation of the behavior of $\mathbf{1}$ to that of $\mathbf{3}$ in the thin film with three classes of metal ions of interest: those expected to be present in nearly every matrix at high concentration (e.g., alkali metal and alkaline earth ions), other metal ions that form fluorescent complexes with $\mathbf{1}$, and those that associate with $\mathbf{1}$ but quench fluorescence. A survey of the responses to $\mathrm{Na}^{+}$and $\mathrm{K}^{+}$indicated that the thin film does not respond to these ions even at high concentrations. $\mathrm{Ca}^{2+}$ forms a complex with 1 with a relatively high quantum yield $\left.\left.\left(\log K_{\mathrm{a}}\right) 3.3, \Phi\right) 0.58\right) ;{ }^{10}$ however, the thin film containing 3 does not respond appreciably to this ion even at relatively high concentrations $(100 \mu \mathrm{M}) . \mathrm{Zn}^{2+}$ also associates with $\left.\left.1\left(\log K_{\mathrm{a}}\right) 4.0, \Phi\right) 0.48\right),{ }^{10}$ and we found that this ion generates a fluorescent response that is approximately half of that observed with the same concentration of $\mathrm{Cd}^{2+}$ (Figure 4A). This difference may be due to the lower quantum yield of the $\mathrm{Zn}^{2+}$ complex and the lower affinity of the chemosensor for this ion, as compared to $\mathrm{Cd}^{2+} . \mathrm{Cu}^{2+}$ forms a stable complex with $\mathbf{1}$ but quenches fluorescence $\left.\left(\log K_{\mathrm{a}}\right) 5.8\right)$. Not only did exposure of the thin film containing 3 to $\mathrm{Cu}^{2+}$ result in no increase in fluorescence, but formation of the $3-\mathrm{Cu}^{2+}$ complex also caused quenching of background fluorescence (Figure 4B). Exposure of the thin film to mixtures of $\mathrm{Cd}^{2+}$ and $\mathrm{Cu}^{2+}$ gave the signature quenching of the latter ion. This result suggests that either 3 in the thin film has a higher affinity for $\mathrm{Cu}^{2+}$ than for $\mathrm{Cd}^{2+}$ or that $\mathrm{Cu}^{2+}$ is capable of quenching the fluorescence of $3-\mathrm{Cd}^{2+}$ complexes.

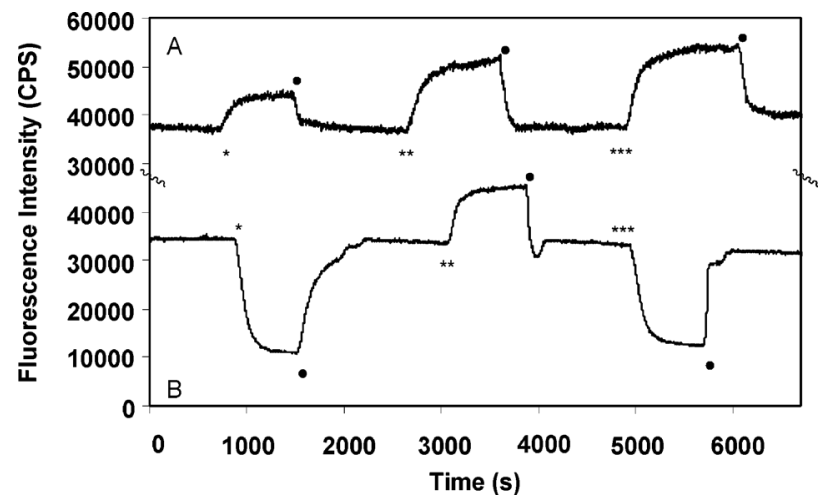

Figure 4. (A) (*) Flow of $\mathrm{Zn}^{2+}$ solution $(10 \mu \mathrm{M})$ initiated. (**) Flow of $\mathrm{Cd}^{2+}$ solution $(10 \mu \mathrm{M})$ initiated. (***) Flow of $\mathrm{Zn}^{2+}(10 \mu \mathrm{M})$ and $\mathrm{Cd}^{2+}(10 \mu \mathrm{M})$ solution initiated. (•) Flow of buffer initiated. (B) (*) Flow of $\mathrm{Cu}^{2+}$ solution $(10 \mu \mathrm{M})$ initiated. (**) Flow of $\mathrm{Cd}^{2+}$ solution $(10 \mu \mathrm{M})$ initiated. (***) Flow of $\mathrm{Cu}^{2+}(10 \mu \mathrm{M})$ and $\mathrm{Cd}^{2+}(10 \mu \mathrm{M})$ solution initiated. $(\bullet)$ Flow of buffer initiated.

We have demonstrated that incorporation of an ionselective chemosensor into a thin film yields materials that can selectively respond to their target metal ion. Use of a polymer intermediary allows immobilization of relatively large quantities of chemosensor in a film sufficiently thin to allow ion diffusion and equilibration in minutes, and the response of the thin film to the target metal ion can be correlated to ion concentration. Consequently, $\mathrm{Cd}^{2+}$ concentrations can be effectively and continuously measured in "real time" in simple solutions. Alkali metal and alkaline earth ions do not interfere with quantification of $\mathrm{Cd}^{2+}$; 
interferents include $\mathrm{Zn}^{2+}$ and $\mathrm{Cu}^{2+}$. Use of additional chemosensors, selective for these interfering metal ions, in arrays is expected to provide a means of quantifying $\mathrm{Cd}^{2+}$ in more complex matrixes. Detection limits of the sensor prototype for $\mathrm{Cd}^{2+}$ are well below those reported by $\mathrm{He}^{8}$ for $\mathrm{K}^{+}$, and because the fluorescent lifetime of the $1-\mathrm{Cd}^{2+}$ complex is much longer than that of the free ligand, ${ }^{10}$ we anticipate that detection limits can be lowered by orders of magnitude using time-resolved spectroscopy.

1108

(1) Cadmium in the Human EnVironment: Toxicity and Carcinogenicity; Nordberg, G. F., Herber, R. F. M., Alessio, L., Eds.; Oxford University Press: Oxford, 1992.

(2) McMurray, C. T.; Tainer, J. A. Nat. Genet. 2003, 34, 239-241.

(3) Alloway, B. J.; Steinnes, E. In Cadmium in Soils and Plant;

McLaughlin, M. J., Singh, B. R., Eds.; Kluwer Academic Publishers:

Boston, 1999; pp 97-118.

(4) Satarug, S.; Baker, J. R.; Urbenjapol, S.; Haswell-Elkins, M.; Reilly, P. E. B.; Williams, D. J.; Moore, M. R. Toxicol. Lett. 2003, 137, 65-83.

(5) For examples, see: (a) EPA methods 600/4-79-020, 600/4-91-010, 600/R-97-072, and 600/R-94-111 (abstracts for these methods can be found on the Internet at www.epa.gov). (b) Garrido, M. L.; Mun oz-Olivas, R.; Ca'mara, C. J. Atomic Spec. 1998, 13, 1145-1149. (c) Zougagh, M.; Garc1'a de Torres, A.; Cano Pavo'n, J. M. Talanta 2002, 56, 753-761.

(6) (a) Ito, S.; Asano, Y.; Wada, H. Talanta 1997, 44. 697-704. (b)

Gupta, V. K.; Kumar, P. Anal. Chim. Acta 1999, 389, 205-212. (c) Couto,

C. M. C. M.; Lima, J. L F. C.; Concieca o, M.; Montenegro, B. S. M.; Reis, B. F.; Zagatto, E. A. G. Anal. Chim. Acta 1998, 366, 155-161. (d)

Suteerapataranon, S.; Jakumnee, J.; Vaneesorn, Y.; Grudpan, K. Talanta 2002, $58,1235-1242$.

(7) For recent reviews, see: (a) Valeur, B.; Leray, I. Coord. Chem. ReV. 2000, 205, 3-40. (b) Prodi, L.; Bolletta, F.; Montalti, M.; Zaccheroni, N. Coord. Chem. ReV. 2000, 205, 59-83.

(8) He, H.; Mortellaro, M. A.; Leiner, M. J. P.; Fraatz, R. J.; Tusa, J. K. J. Am. Chem. Soc. 2003, 125, 1468-1469.

(9) van der Veen, N. J.; Flink, S.; Deij, M. A.; Egberink, R. J. M.; van

Veggel, F. C. J. M.; Reinhoudt, D. N. J. Am. Chem. Soc. 2000, 122, 6112-

6113.

(10) Prodi, L.; Montalti, M.; Zaccheroni, N.; Bradshaw, J. S.; Izatt, R. M.; Savage, P. B. Tetrahedron Lett. 2001, 42, 2941.

(11) Bradshaw, J. S.; Krokowiak, K. E.: Bruening, R. L.; Tarbet, B, J.; Savage, P. B.; Izatt, R. M. J. Org. Chem. 1988, 53, 3190.

(12) Angst, D. L.; Simmons, G. W. Langmuir 1991, 7, 2236-2242.
Acknowledgment. Financial support from Brigham Young University is gratefully acknowledged.

Supporting Information Available: Experimental procedures for preparation of $\mathbf{2}$ and $\mathbf{3}$ and methods used in making monolayers and thin films. This material is available free of charge via the Internet at http://pubs.acs.org. 